\title{
Effect of Temperature on Corrosion Behavior of X65 Steel in Simulated Deep Sea Environment
}

\author{
Liqin Wang, Zhiming Gao*, Yingjie Liu, Xibo Lu, Can Wang, Wenbin Hu \\ School of Material Science and Technology, Tianjin University, Tianjin, 30072, China \\ Engineering Research Center of Composite and Functional Materials,Ministry of Education, Tianjin, \\ 30350, China \\ "E-mail: gaozhiming@tju.edu.cn
}

doi: $10.20964 / 2019.01 .29$

Received: 9 September 2018 / Accepted: 16 October 2018 / Published: 30 November 2018

\begin{abstract}
The influence of temperature on the corrosion behavior of X65 steel under simulated abyssal conditions have been investigated using electrochemical methods, Raman spectroscopy and 3D microscopy. EIS results indicated that the $\mathrm{R}_{\mathrm{ct}}$ (charge transfer resistance) decreased gradually and the film density of the corrosion layer decreased with increasing temperatures. Polarization curves indicated that the corrosion current densities increased and the self-corrosion potentials shifted negatively with increasing temperatures. The corrosion morphology manifested that the dense corrosion product films were formed at lower temperatures with pitting corrosion occurring, whilst the corrosion product films had cracks at higher temperatures and the corrosion of X65 steel featured uniform corrosion. The results of Raman spectroscopy showed that the corrosion products were comprised of $\gamma-\mathrm{FeOOH}$ and $\mathrm{Fe}_{3} \mathrm{O}_{4}$ at $5^{\circ} \mathrm{C}$, while they contained $\gamma-\mathrm{FeOOH}$ and $\alpha-\mathrm{FeOOH}$ at $25^{\circ} \mathrm{C}$. Therefore, the corrosion resistance properties of X65 pipeline steel in abyssal environments decreased as temperature increased.
\end{abstract}

Keywords: X65 pipeline steel, deep sea environments, temperature, hydrostatic pressure.

\section{$\underline{\text { FULL TEXT }}$}

(C) 2019 The Authors. Published by ESG (www.electrochemsci.org). This article is an open access article distributed under the terms and conditions of the Creative Commons Attribution license (http://creativecommons.org/licenses/by/4.0/). 